\title{
The Evaluation of the Antioxidant and Intestinal Protective Effects of Baicalin-Copper in Deoxynivalenol-Challenged Piglets
}

\author{
Andong Zha $\mathbb{D}^{1,2}$ Daixiu Yuan, ${ }^{3}$ Zhijuan Cui, ${ }^{1}$ Ming Qi, ${ }^{1,2}$ Simeng Liao, ${ }^{1,2}$ Peng Liao $\mathbb{D},{ }^{1}$ \\ and Bie Tan iD 1 \\ ${ }^{1}$ Institute of Subtropical Agriculture, Chinese Academy of Sciences, Changsha, Hunan 410125, China \\ ${ }^{2}$ University of Chinese Academy of Sciences, Beijing 100008, China \\ ${ }^{3}$ Department of Medicine, Jishou University, Jishou, Hunan 416000, China
}

Correspondence should be addressed to Peng Liao; liaopeng@isa.ac.cn

Received 25 September 2019; Revised 25 November 2019; Accepted 3 December 2019; Published 22 January 2020

Academic Editor: Christopher Horst Lillig

Copyright ( 2020 Andong Zha et al. This is an open access article distributed under the Creative Commons Attribution License, which permits unrestricted use, distribution, and reproduction in any medium, provided the original work is properly cited.

\begin{abstract}
The present study was performed to evaluate the antioxidant and intestinal protective effects of baicalin-copper on deoxynivalenolchallenged piglets. Forty weaned piglets were randomly divided into four groups and assigned to different diets: (1) basal diet (Con), (2) $4 \mathrm{mg} / \mathrm{kg}$ deoxynivalenol of basal diet (DON), (3) $5 \mathrm{~g} / \mathrm{kg}$ baicalin-copper of basal diet (BCU); and (4) $4 \mathrm{mg} / \mathrm{kg}$ deoxynivalenol $+5 \mathrm{~g} / \mathrm{kg}$ baicalin-copper of basal diet (DBCU). The results showed that the ADFI and ADG of piglets in the DON group were markedly lower than those in the Con group, but the ADFI and ADG of the DBCU group were not significantly different from those of the Con group. In piglets fed a DON-contaminated diet, dietary supplementation with BCU significantly decreased the mRNA levels of P70S6K, 4E-BP1, and HSP70 in the liver, the protein expression of HO-1 in the jejunum, and the expression of p-Nrf2 and p-NF- $\kappa$ B in the ileum but increased Mn-SOD activity in serum. Dietary supplementation with BCU increased jejunal maltase, ZIP4 and MT mRNA levels, and serum concentrations of Arg, Val, Ile, Leu, Lys, and Tyr in DON-contaminated piglets. In summary, BCU can alleviate the growth impairment induced by DON and enhance antioxidant capacity and nutrition absorption in piglets fed DON-contaminated diets.
\end{abstract}

\section{Introduction}

Deoxynivalenol (DON) is a trichothecene mycotoxin that is mainly produced by Fusarium graminearum and Fusarium culmorum and is named for its ability to cause nausea and vomiting in animals $[1,2]$. DON pollution is common worldwide, and DON has the highest detection rate and overstandard rate among all mycotoxins [3-6]. DON promotes oxidative stress, changes intestinal morphology, and affects nutrient absorption. Additionally, pigs fed a DONcontaminated diet can show growth retardation, weight loss, anorexia, and other toxicity symptoms [7-9]. Some studies have also noted that DON can affect the body's immune regulation mechanism and that DON can induce the activation of the NF- $\kappa \mathrm{B}$ pathway and promote the upregulation of a series of cytokines at the protein and mRNA levels. In addition, DON has reproductive genotoxicity, which can reduce fetal quality and increase fetal mortality. A previous study showed that DON can cause morphological damage in intestinal villi epithelial cells in pigs, resulting in the reduced intake or even refusal of food and damaging antioxidant capacity $[10,11]$.

Baicalin-copper (BCU) is a complex of baicalin and copper ions. Baicalin is extracted from Scutellaria baicalensis, and it is a flavonoid. Baicalin can clear free radicals to avoid oxidative damage, has anti-inflammatory and anticancer effects, and promotes cellular and humoral immunity [12-14]. A previous study showed that baicalin easily chelates with $\mathrm{Zn}^{2+}$ or $\mathrm{Cu}^{2+}$ to form a metal chelate compound, which has a stronger oxygen free radical-scavenging effect than does the baicalin monomer [15]. Li et al. showed that baicalin-copper induces apoptosis in HepG2 cells by downregulating the PI3K/Akt/mTOR signaling pathway and that baicalin-copper reduced the liver relative index, increasing the SOD content in the liver 
TABLE 1: Mycotoxin content in contaminated feed $(n=6)$.

\begin{tabular}{lccc}
\hline Items & $\begin{array}{c}\mathrm{AFB}_{1} \\
(\mu \mathrm{g} / \mathrm{kg})\end{array}$ & $\begin{array}{c}\mathrm{DON} \\
(\mu \mathrm{g} / \mathrm{kg})\end{array}$ & $\begin{array}{c}\mathrm{ZEN} \\
(\mu \mathrm{g} / \mathrm{kg})\end{array}$ \\
\hline Limit of detection & 1 & 100 & 10 \\
Basal feed & Undetected & 124 & 53 \\
DON-contaminated feed & 7.3 & 7964 & 12.56 \\
\hline
\end{tabular}

[16]. In an acute toxicity test, Liu et al. showed that BCU not only is nontoxic to mice but also has good antibacterial and antitumor activity [17].

Based on the function of $\mathrm{BCU}$, we hypothesize that the addition of BCU to the diet can alleviate intestinal damage, promote antioxidant capacity, and improve growth performance. The objective of this experiment was to investigate the effects of BCU on intestinal antioxidative damage using a piglet model of DON-induced oxidative stress.

\section{Materials and Methods}

2.1. Preparation of DON-Contaminated Feed and BCU. The DON-contaminated diet was prepared according to previous studies $[9,18]$. The contents of mycotoxins in the diet were detected by liquid chromatography (Beijing Taileqi, Qingdao, China). Table 1 shows the toxin content in the basal diet: the DON content in the basal diet was $124 \mu \mathrm{g} / \mathrm{kg}$, the DON content in the DON-contaminated diet was $7964 \mu \mathrm{g} / \mathrm{kg}$, and the $\mathrm{AFB}_{1}$ and ZEN contents were low in the basal diet and DON-contaminated diet. Before the experiment, basal diet was added to the DON-contaminated diet to reach a DON content of $4 \mathrm{mg} / \mathrm{kg}$ diet. The concentration of DON was chosen according to previous studies $[19,20]$. The synthesis of BCU was based on a previous study $[16,17]$. The dose of BZN used in the present experiment was based on a preliminary test.

2.2. Animals, Diets, and Experimental Design. Our study included 40 weaned piglets $(21 \mathrm{~d})$ as experimental animals. All piglets were provided by New Wellful (New Wellful Co. Ltd., Changsha, China). Forty pigs were randomly divided into 4 groups with 10 repeats in each group and fed different diets: (1) basal diet (Con group), (2) $4 \mathrm{mg} / \mathrm{kg}$ deoxynivalenol of basal diet (DON group), (3) $5 \mathrm{~g} / \mathrm{kg}$ baicalin-copper of basal diet (BCU group), and (4) $4 \mathrm{mg} / \mathrm{kg}$ deoxynivalenol $+5 \mathrm{~g} / \mathrm{kg}$ baicalin-copper of basal diet (DBCU group). The basal diet was a corn-soybean mash diet. According to NRC (2012), weaned piglets' nutritional needs and the ideal amino acid model preparation for pigs, the basic diet composition, and the nutrient level are shown in Table 2 [21]. The experimental design and all procedures involving animals were approved by the Animal Care and Use Committee of the Institute of Subtropical Agriculture at the Chinese Academy of Sciences.

2.3. Animal Management and Sample Collection. The piglets were housed individually in stalls with a slatted floor, and the room temperature was maintained at approximately $30^{\circ} \mathrm{C}$. The piglets had free access to food and water. The piglets
TABLe 2: Composition and nutrient level of the diets.

\begin{tabular}{lccc}
\hline Ingredients & Content (\%) & Nutrient levels & Content \\
\hline Corn & 63.70 & DE (MJ/kg) & 14.60 \\
Soybean meal & 19.80 & CP (\%) & 20.27 \\
Whey dried & 4.30 & Calcium (\%) & 0.69 \\
Fish meal & 9.00 & Phosphorus (\%) & 0.57 \\
Soybean oil & 0.80 & Lysine (\%) & 1.26 \\
Lysine & 0.38 & Threonine (\%) & 0.76 \\
Methionine & 0.10 & Met+Cys (\%) & 0.62 \\
Threonine & 0.09 & Tryptophan (\%) & 0.20 \\
Tryptophan & 0.01 & Arginine (\%) & 1.09 \\
Limestone & 0.52 & Histidine (\%) & 0.44 \\
NaCl & 0.30 & Isoleucine (\%) & 0.71 \\
Premix* & 1.00 & Leucine (\%) & 1.52 \\
& & Phenylalanine (\%) & 0.81 \\
& & Valine (\%) & 0.72 \\
\hline
\end{tabular}

${ }^{*}$ The premix feed contain Cu $5 \mathrm{mg}$, Se $0.3 \mathrm{mg}$, I $0.1 \mathrm{mg}$, Fe $80 \mathrm{mg}$, Zn $85 \mathrm{mg}$, Mn $3 \mathrm{mg}$, vitamin $B_{1} 1 \mathrm{mg}$, vitamin $B_{2} 3 \mathrm{mg}$, vitamin $B_{3} 12.5 \mathrm{mg}$, vitamin $B_{6}$ $1.6 \mathrm{mg}$, vitamin $B_{5} 10 \mathrm{mg}$, vitamin A $2000 \mathrm{IU}$, vitamin $B_{12} 0.016 \mathrm{mg}$, vitamin $\mathrm{D}_{3} 200 \mathrm{IU}$, vitamin E $12 \mathrm{IU}$, vitamin $\mathrm{K} 0.5 \mathrm{mg}$, folic acid $0.3 \mathrm{mg}$, choline chloride $0.5 \mathrm{mg}$, vitamin $\mathrm{B}_{7} 0.05 \mathrm{mg}$.

were acclimated to the basal diet for three days before beginning the experiment. During the experiment, the piglets were fed 4 times per day, and the feeding times were 7:30, 11:00, 14:30, and 18:00. The experiment lasted for 14 days $[8,22]$. During the trial, one piglet in the Con group died. On the morning of the $15^{\text {th }}$ day, we calculated the growth performance index and randomly selected 7 piglets from each group to slaughter. The samples were stored at $-80^{\circ} \mathrm{C}$. The following growth performance equations were used:

$\mathrm{ADG}=($ final weight - initial weight $) /$ experimental period $(\mathrm{g} / \mathrm{d})$,

$\mathrm{ADFI}=$ total feed intake/experimental period $(\mathrm{g} / \mathrm{d})$,

$\mathrm{F} / \mathrm{D}=$ total feed intake $/($ final weight - initial weight $)$,

Relative organ weight $(\%)=($ organ weight $/$ body weight $) \times 100$.

2.4. Intestinal Morphology. First, $2 \mathrm{~cm}$ of the jejunum was collected, the chyme was washed, and the sample was fixed in a $4 \%$ paraformaldehyde solution. Then, the sample was dehydrated with gradient alcohol solutions and embedded in paraffin. Second, $5 \mathrm{~mm}$ slices were prepared and stained with hematoxylin-eosin. Third, microscopes were used to observe the samples, and computer-aided systems were used to photograph the samples. Finally, an image analysis system was used to measure villi length and crypt length [23, 24].

2.5. Determination of Antioxidant Capacity and Free Amino Acids in the Serum and Digestive Enzyme Activity in the Intestine. Blood samples were naturally placed at $4^{\circ} \mathrm{C}$ for 1 hour and centrifuged for 10 minutes $(3000 \mathrm{rpm})$, and the serum was collected. The samples were analyzed in the Laboratory of Animal and Molecular Nutrition of the Institute 
of Subtropical Agriculture, Chinese Academy of Sciences. The experiments were performed according to the instructions of the ELISA kit (Nanjing Jiancheng Bioengineering Institute, Nanjing, China). The indexes of the serum antioxidant capacity included T-SOD $(\mathrm{U} / \mathrm{ml})$, CuZn-SOD $(\mathrm{U} / \mathrm{ml})$, Mn-SOD (U/ml), GSH-P $x$ (U/ml), T-AOC (mmol/gprot), GSH $(\mathrm{U} / \mathrm{ml}), \mathrm{MDA}(\mathrm{nmol} / \mathrm{ml})$, and $\mathrm{NO}(\mu \mathrm{mol} / \mathrm{l})$ [25-27]. The indexes of the chyme digestive enzyme activity included trypsin, lipase, maltase, sucrase, and total protein.

Serum free amino acid content was determined using an Ultimate 3000 HPLC and AB 3200 Q TRAP LC-MS/MS. The indexes included L-histidine (His), L-serine (Ser), L-arginine (Arg), glutamic acid or glutamine (Glx), L-aspartic acid or L-asparagine (Asx), L-glutamate (Glu), L-threonine (Thr), L-alanine (Ala), L-proline (Pro), L-cystine (Cys), L-lysine (Lys), L-tyrosine (Tyr), L-methionine (Met), L-valine (Val), L-leucine (Leu), L-isoleucine (Ile) [28, 29].

2.6. Quantification of mRNA by Real-Time PCR Analysis. According to previous studies, the tissues were milled in liquid nitrogen, and RNA was extracted by the TRIzol method. Based on the cDNA sequence of pigs, primers were designed by Primer 5.0 (Table 3 ). Real-time polymerase chain reaction (PCR) was performed, and the results were calculated as previously described $[24,30]$.

2.7. Western Blotting. According to the instructions of the BCA protein assay kit (Wellbio, Changsha, China), we measured the protein concentration in the experiment. The protein was separated by a $4.8 \%$ SDS-PAGE stacking gel and a $10 \%$ SDS-PAGE separating gel. The protein was transferred to an NC membrane and blocked with 5\% skim milk powder. Then, suitable primary and secondary antibodies were used (as in Table 4). Ultimately, an enhanced chemiluminescence (ECL) solution (Thermo Fisher Scientific, Waltham, USA) was used for color exposure, and Image-Pro Plus software was used for protein grayscale analysis $[10,31]$.

2.8. Statistical Analysis. All data were sorted out by Excel (Microsoft, Redmond, USA), one-way ANOVA was conducted with SPSS 20 (IBM, Armonk, USA), and multiple comparisons were performed with Duncan's multiple comparisons. The data of each group were expressed as the mean \pm SEM; the significant difference criterion was $p<0.05$. All figures were prepared with GraphPad Prism 7.0 (GraphPad Software, San Diego, USA).

\section{Results}

3.1. Growth Performance and Relative Organ Weights. As shown in Table 5, there was no marked difference in initial weight of the four groups. The final weight, ADFI, and ADG of the DON group were significantly lower than those of the Con group $(p<0.05)$. Compared with the DON group and Con group, the DBCU group did not show marked changes in final weight, ADFI, and ADG. There was no significant difference between the Con group and the $\mathrm{BCU}$ group. In addition, no differences in $F / G$ were detected among the four groups.
As shown in Table 6, there was no remarkable difference between the Con group and the BCU group in the relative organ weights of the heart, lung, and kidney. However, the relative weight of the liver in the DBCU group was significantly lower than that in the Con, DON, and BCU groups $(p<0.05)$. In addition, the relative spleen weight was decreased in piglets fed a DON-supplemented diet compared with piglets in the Con and BCU groups $(p<0.05)$, whereas there was no significant difference among the Con, BCU, and DBCU groups.

3.2. Serum Antioxidant Capacity. As Figure 1 shows, although there was no difference in T-SOD activity among the four groups, the Mn-SOD activity in the DON group was significantly lower than that in the Con group $(p<0.05)$, and the Mn-SOD activity in the DBCU group was not different from that in the Con group. The GSH activity of piglets fed $\mathrm{BCU}$ was increased compared with that of piglets in the Con group $(p<0.05)$. There was no difference in GSH activity between the DON group and the Con group, but the GSH activity of the DBCU group was significantly higher than that of the Con group $(p<0.05)$. The NO content of the DON group and BCU group was not significantly different from that of the Con group, but the NO content of the DBCU group was significantly lower than that of the Con group $(p<0.05)$.

3.3. Intestinal Morphology. As illustrated in Figure 2, the jejunum villus height was not decreased in the DON and BCU groups compared with the Con group, but the jejunum villus height of the DBCU group was significantly reduced compared with that of the Con group $(p<0.05)$. There was no remarkable difference in crypt depth among the Con, DON, and DBCU groups, while the piglets fed the BCUsupplemented diet had a markedly increased crypt depth in the jejunum $(p<0.05)$.

3.4. Expression of Oxidative Stress-Related Genes in the Liver. DON can cause oxidative stress in the body, and the liver is an organ with antioxidant and detoxifying functions, so we tested the mRNA expression of antioxidant genes in the liver. As shown in Figure 3, P70S6K, 4E-BP1, and HSP70 mRNA expression levels were markedly increased in piglets fed the DON-supplemented diet compared with piglet in the Con group $(p<0.05)$; however, the P70S6K mRNA expression in the DBCU group was remarkably lower than that in the Con group $(p<0.05)$. The $4 \mathrm{E}-\mathrm{BP} 1$ and HSP70 mRNA expression levels in the DBCU group were not different from those in the Con group. In addition, the HO-1 mRNA expression of the $\mathrm{DBCU}$ group was significantly higher than that in the Con group $(p<0.05)$. The P70S6K mRNA expression of the BCU group was lower than that of the Con group, and AMPK $\alpha 2$ mRNA expression was higher than that in the Con group $(p<0.05)$. Compared with the DBCU group, the P70S6K, 4E-BP1, and HSP70 mRNA expression levels in the DON group were increased $(p<0.05)$, and the HO- 1 and AMPK $\alpha 2$ mRNA expression levels in the DON group were decreased $(p<0.05)$. 
TABLE 3: Primers used for RT-PCR.

\begin{tabular}{|c|c|c|c|c|}
\hline Gene & Primer sequence $\left(5^{\prime}-3^{\prime}\right)$ & Accession number & Size (bp) & $\operatorname{Tm}\left({ }^{\circ} \mathrm{C}\right)$ \\
\hline \multirow{2}{*}{ Nrf2 } & CACCACCTCAGGGTAATA & \multirow{2}{*}{ XM_021075133.1 } & \multirow{2}{*}{125} & \multirow{2}{*}{60} \\
\hline & GCGGCTTGAATGTTTGTC & & & \\
\hline \multirow{2}{*}{$\mathrm{HO}-1$} & AGCTGTTTCTGAGCCTCCAA & \multirow{2}{*}{ NM_001004027.1 } & \multirow{2}{*}{130} & \multirow{2}{*}{60} \\
\hline & CAAGACGGAAACACGAGACA & & & \\
\hline \multirow{2}{*}{ NQO1 } & CCAGCAGCCCGGCCAATCTG & \multirow{2}{*}{ NM_001159613.1 } & \multirow{2}{*}{160} & \multirow{2}{*}{60} \\
\hline & AGGTCCGACACGGCGACCTC & & & \\
\hline \multirow{2}{*}{$\mathrm{NF}-\kappa \mathrm{B}$} & AGCCATTGACGTGATCCAGG & \multirow{2}{*}{ NM_001048232.1 } & \multirow{2}{*}{248} & \multirow{2}{*}{60} \\
\hline & CGAAATCGTGGGGCACTTTG & & & \\
\hline \multirow{2}{*}{$\mathrm{AMPK} \alpha 2$} & CGACGTGGAGCTGTACTGCTT & \multirow{2}{*}{ XM_021091195.1 } & \multirow{2}{*}{143} & \multirow{2}{*}{60} \\
\hline & CATAGGTCAGGCAGAACTTGC & & & \\
\hline \multirow{2}{*}{ P70S6K } & GGAAACAAGTGGAATAGAGCAGATG & \multirow{2}{*}{ XM_021067294.1 } & \multirow{2}{*}{65} & \multirow{2}{*}{60} \\
\hline & TTGGAAGTGGTGCAGAAGCTT & & & \\
\hline \multirow{2}{*}{$4 \mathrm{E}-\mathrm{BP} 1$} & CCGGAAGTTCCTAATGGAGTGT & \multirow{2}{*}{ NM_001244225.1 } & & \\
\hline & GGTTCTGGCTGGCATCTGT & & 125 & 60 \\
\hline HSD70 & GTGGCTCTACCCGCATCCC & NMM 001122127 & 114 & 60 \\
\hline ПगР 70 & GCACAGCAGCACCATAGGC & NM_00112312/.1 & 114 & 00 \\
\hline Aminonentidace & TCATCAATCGGGCTCAGGTC & XM 0056525243 & 101 & 61 \\
\hline Amminopeptidase $\mathrm{N}$ & TCCGTTCAGGAAGAGGGTGTT & AIVI_005035324.J & 101 & 01 \\
\hline Maltase & TGCCTTACCTCTACACGCTGATGC & XM 0210790951 & 232 & 65 \\
\hline & GATTCACTGCCAGATTCCGTGCTAT & & & 65 \\
\hline $7 \mathrm{nT} 1$ & CCAGGGGAGCAGGGAACCGA & NM 0011304701 & 73 & 65 \\
\hline $\operatorname{Ln} 11$ & TCAGCCCGTTGGAGTTGCTGC & NM_0011394/0.1 & $/ 3$ & 65 \\
\hline $\mathrm{ZnT2}$ & GACAGCGCCAGCCAGCATCA & NM 0011394751 & 09 & 65 \\
\hline $\operatorname{Ln} 12$ & GGCAGCCACCAAAACGCCCA & NM_0011394/5.1 & 99 & 65 \\
\hline $7 \mathrm{nT5}$ & ACCAGTCTCAGTTGGAGGGCTGA & NM 0011376241 & 70 & 65 \\
\hline $\operatorname{Ln} 15$ & TCCATGGGTATGGGTGTGGGCA & NM_00113/624.1 & 19 & 65 \\
\hline 7IP4 & TGCTGAACTTGGCATCTGGG & YM 0210004401 & 125 & 60 \\
\hline ZIP4 & CGCCACGTAGAGAAAGAGGC & XM1_021090449.1 & 125 & 60 \\
\hline DMT1 & CGCGCTTCGCCCGAGTGAT & YM 0210817101 & 70 & 66 \\
\hline DMT1 & TGGAAGACGGCCACCAGCAGA & XM1_021081710.1 & 70 & 66 \\
\hline $\mathrm{MT}$ & GTGAATCCGCGTTGCTCTCTGCT & XM 0210938911 & 72 & 66 \\
\hline & CTGTGGGGCAGGAGCAGTTGG & & & \\
\hline TasR3 & GCTGGGCGACAGGACAG & NM 0011122881 & 102 & 60 \\
\hline 1 ASKJ & TTGATTTCCTCCACAGCCAT & NM_001113288.1 & 102 & 60 \\
\hline GPR40 & TGCTCTGACCTCCTGCTGG & XM 0139982892 & 235 & 60 \\
\hline$G P K 40$ & CACACACCCCCCAGGAATAG & XM_013998289.2 & 235 & 60 \\
\hline GPR43 & CGTGTTCATCGTTCAGTA & XM 0210931961 & 76 & 52 \\
\hline$G P K 4 J$ & GAAGTTCTCATAGCAGGTA & AIV_021095190.1 & 10 & 32 \\
\hline GAPDH & АСАСТСАСТСТТСТАССТТТG & XM 021091114.1 & 90 & 60 \\
\hline & CAAATTCATTGTCGTACCAG & & & \\
\hline
\end{tabular}

3.5. Western Blotting of Intestinal Samples. DON is mainly absorbed in the intestine, so we investigated whether DON affects the expression of antioxidant proteins. As shown in Figure 4, in the jejunum, compared with piglets in the Con, BCU, and DBCU groups, the piglets in the DON group showed markedly increased $\mathrm{HO}-1$ expression. As shown in Figure 5, in the ileum, compared with piglets in the Con group, piglets of the DON group showed markedly increased protein expression levels of $\mathrm{p}-\mathrm{Nrf} 2, \mathrm{p}-\mathrm{NF}-\kappa \mathrm{B}$, and HO-1 $(p<0.05)$, while piglets fed the DON and BCU supplemented diet showed decreased p-Nrf2 and p$\mathrm{NF}-\kappa \mathrm{B}$ expression levels in compare with DON group $(p<0.05)$. There was no difference in $\mathrm{p}-\mathrm{Nrf} 2, \mathrm{p}-\mathrm{NF}-\kappa \mathrm{B}$, and $\mathrm{HO}-1$ expression between the Con and BZN groups.

3.6. Serum Free Amino Acids. Figure 6 shows the results. Piglets fed the DON-supplemented diet showed significantly decreased Ser, Asx, Glu, Met, Ile, and Leu content in serum 
TABLe 4: Antibody information used in Western blotting.

\begin{tabular}{lccc}
\hline First antibody & Company & Catalog number & Titers \\
\hline P70S6K & Abcam & ab9366 & $1: 250$ \\
p-P70S6K & LSBio & LS-C124497 & $1: 500$ \\
HO-1 & Abcam & ab52947 & $1: 2000$ \\
mTOR & Proteintech & 20657-1-AP & $1: 300$ \\
p-mTOR & Abcam & ab109268 & $1: 1000$ \\
NF- $\kappa B$ & Proteintech & $10745-1-A P$ & $1: 500$ \\
p-NF- $\kappa$ B & Abcam & ab86299 & $1: 2000$ \\
Nrf2 & Abcam & ab92946 & $1: 1000$ \\
p-Nrf2 & Bioss & bs-2013R & $1: 500$ \\
$\beta$-Actin & Proteintech & $60008-1-I g$ & $1: 5000$ \\
\hline
\end{tabular}

$(p<0.05)$, while piglets fed the BCU-supplemented diet showed significantly decreased Asx, Glu, Met, and Pro content $(p<0.05)$. Compared with the DON group, the DBCU group had obviously decreased Asx content and the DBCU group had clearly enhanced Ile, Arg, Leu, Tyr, and Lys content $(p<0.05)$.

3.7. Intestinal Nutrition Digestive and Absorption-Related Gene Expressions. As shown in Figure 7, compared with the control diet, dietary supplementation with BCU at $5 \mathrm{~g} / \mathrm{kg}$ diet reduced the maltase activity in the chyme $(p<0.05)$, but there was no evident difference in maltase activity between the BCU and DBCU groups. In the jejunum, the maltase mRNA levels of the DBCU group were significantly higher than that of the other groups $(p<0.05)$. In the ileum, the aminopeptidase $\mathrm{N}$ and maltase mRNA levels in the DON group were significantly higher than those in the Con group $(p<0.05)$, the aminopeptidase $\mathrm{N}$ mRNA levels in the DBCU group were significantly lower than those in the Con group and the DON group $(p<0.05)$. The aminopeptidase $\mathrm{N}$ and maltase mRNA levels in the BCU group were not significantly different from those in the Con group.

As shown in Figure 8, in the jejunum, the TasR3 and GPR41 mRNA levels in the DON group were significantly higher than those in the other three groups $(p<0.05)$, while there was no significant difference in TasR3 and GPR41 mRNA levels among the Con, BCU, and DBCU groups. In the ileum, no differences in GPR40 mRNA expression were detected compared with the Con group, while GPR40 mRNA levels in DBCU group were significantly reduced $(p<0.05)$.

As Figure 9 shows, in the jejunum, the mRNA level of ZNT5 in the DON group was significantly higher than that in the Con group $(p<0.05)$. The ZNT5 mRNA level in the DBCU group was significantly lower than that in the DON group $(p<0.05)$, while the ZIP4 and MT mRNA levels in the DBCU group were significantly higher than those in the DON group $(p<0.05)$. In the ileum, the MT mRNA level in the DON group was significantly lower than that in the Con group. The ZNT5 mRNA level in the DBCU group was significantly higher than that in the Con group, the MT mRNA level in the DBCU group was significantly higher than that in the DON group, and the DMT1 mRNA level in the DBCU group was significantly lower than that in the Con group and the DON group. The ZNT5 mRNA level in the BCU group was significantly higher than that in the Con group, and the DMT1 mRNA level in the BCU group was significantly lower than that in the Con group.

\section{Discussion}

The degree of DON contamination in grain is the highest among fusarium toxins and poses a large threat to animal health. Previous studies showed that deoxynivalenol reduced or mutilated feeding and caused vomiting and weight loss. Xiao et al. found that DON significantly reduced ADG and ADFI in weaned piglets through a 30-day feeding trial [8]. Li et al. also showed that piglets fed a DON-contaminated diet showed significantly decreased growth performance [32]. Goyarts et al. found that DON did not change the feed-to-gain ratio of grower pigs, while Bergsjo et al. showed that grower piglets fed DON-contaminated diets had reduced feed utilization efficiency $[33,34]$. Baicalin is a kind of flavonoid compound. Some studies have also shown that dietary flavonoid supplementation can ameliorate oxidative stress and improve the growth performance of broilers and pigs [35-38]. The results of the current study show that dietary supplementation with DON at $4 \mathrm{mg} / \mathrm{kg}$ diet significantly decreased ADFI and ADG, and did not impact $F / G$. However, dietary supplementation with BCU and DON did not change the ADFI and ADG in compare with Con group, which means that dietary supplementation with BCU can improve growth performance in deoxynivalenolchallenged piglets. It has also been shown that oral DON administration in mice causes a hepatic inflammatory response and spleen immune dysfunction [39, 40]. Different studies have shown different effects of DON on relative organ weight $[41,42]$. In the current study, the relative liver weight of the DBCU group was obviously decreased compared with that of the DON group, and the relative spleen weight of the DBCU group tended to be higher than that of the DON group. This result may be attributed to the protective effect of baicalin on the liver and spleen, as previous studies showed [16, 43, 44].

Previous studies have suggested a toxicological mechanism of deoxynivalenol: DON binds with the $80 \mathrm{~S}$ subunit on the ribosome in eukaryotic cells, activates the MAPK pathway, produces an oxidative stress response, inhibits the synthesis of DNA and proteins, and thus produces cytotoxicity and immunotoxicity [45-48]. In contrast, baicalin, a kind of flavonoid compound, has a good antioxidant effect. Previous studies have reported that, on the one hand, flavonoids can affect enzyme activity, including enhancing antioxidant activity and inhibiting oxidase activity; on the other hand, flavonoids directly remove reactive oxygen species [49-52]. To understand the effects of DON and BCU on the antioxidant capacity of piglets, we first measured the serum antioxidant index of piglets. In the current study, dietary supplementation with DON reduced Mn-SOD activity in serum and BCU partly alleviated the effect of DON on Mn-SOD activity. Dietary supplementation with DON and BCU markedly reduced the concentration of $\mathrm{NO}$ in serum. 
TABLE 5: Effects of BCU on growth performance of piglets challenged with DON $(n=7)$.

\begin{tabular}{|c|c|c|c|c|c|c|}
\hline Item & Con & DON & $\mathrm{BCU}$ & $\mathrm{DBCU}$ & SEM & $p$ value \\
\hline Initial weight (kg) & 6.036 & 6.007 & 6.414 & 6.129 & 0.13 & 0.696 \\
\hline Final weight (kg) & $9.343^{\mathrm{ab}}$ & $8.236^{\mathrm{b}}$ & $9.736^{\mathrm{a}}$ & $8.786^{\mathrm{ab}}$ & 0.206 & 0.044 \\
\hline $\operatorname{ADFI}(\mathrm{g} / \mathrm{d})$ & $315.816^{\mathrm{a}}$ & $227.551^{\mathrm{b}}$ & $321.939^{\mathrm{a}}$ & $277.551^{\mathrm{ab}}$ & 12.054 & 0.012 \\
\hline $\mathrm{ADG}(\mathrm{g} / \mathrm{d})$ & $236.226^{\mathrm{a}}$ & $159.183^{b}$ & $237.246^{\mathrm{a}}$ & $189.796^{\mathrm{ab}}$ & 9.84 & 0.004 \\
\hline $\mathrm{F} / \mathrm{G}$ & 1.338 & 1.434 & 1.365 & 1.501 & 0.031 & 0.255 \\
\hline
\end{tabular}

${ }^{\mathrm{a}, \mathrm{b}}$ Means in the same row with different superscripts differ $(p<0.05)$. Con: basal diet; DON: $4 \mathrm{mg} / \mathrm{kg}$ deoxynivalenol of basal diet; BCU: $5 \mathrm{~g} / \mathrm{kg}$ baicalin-copper of basal diet, DBCU: $4 \mathrm{mg} / \mathrm{kg}$ deoxynivalenol $+5 \mathrm{~g} / \mathrm{kg}$ baicalin-copper of basal diet.

TABLE 6: Effects of BCU on relative organ weights of piglets challenged with DON $(n=7)$.

\begin{tabular}{|c|c|c|c|c|c|c|}
\hline Item & Con & DON & $\mathrm{BCU}$ & DBCU & SEM & $p$ value \\
\hline Heart (\%) & 0.509 & 0.486 & 0.481 & 0.457 & 0.469 & 0.069 \\
\hline Liver (\%) & $2.530^{\mathrm{a}}$ & $2.523^{\mathrm{a}}$ & $2.386^{\mathrm{a}}$ & $2.166^{\mathrm{b}}$ & 2.313 & 0.003 \\
\hline Spleen (\%) & $0.254^{\mathrm{a}}$ & $0.186^{\mathrm{b}}$ & $0.257^{\mathrm{a}}$ & $0.224^{\mathrm{ab}}$ & 0.209 & 0.047 \\
\hline Lung (\%) & 1.354 & 1.170 & 1.266 & 1.211 & 1.175 & 0.330 \\
\hline Kidney (\%) & 0.639 & 0.553 & 0.614 & 0.551 & 0.556 & 0.129 \\
\hline
\end{tabular}

${ }_{\mathrm{a}, \mathrm{b}}$ Means in the same row with different superscripts differ $(p<0.05)$. Con: basal diet; DON: $4 \mathrm{mg} / \mathrm{kg}$ deoxynivalenol of basal diet; BCU: $5 \mathrm{~g} / \mathrm{kg}$ baicalin-copper of basal diet; DBCU: $4 \mathrm{mg} / \mathrm{kg}$ deoxynivalenol $+5 \mathrm{~g} / \mathrm{kg}$ baicalin-copper of basal diet.

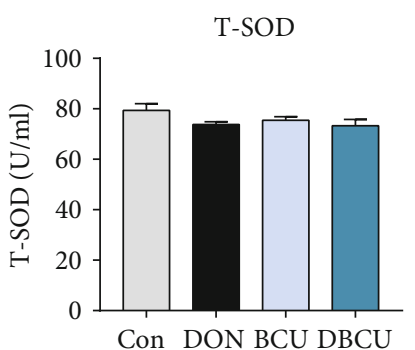

GSH-P $x$

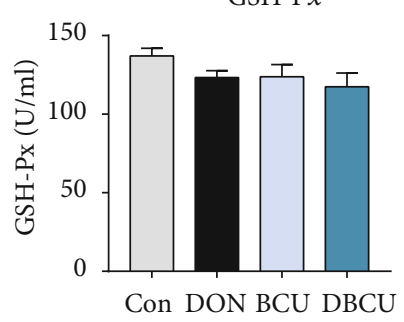

CuZn-SOD

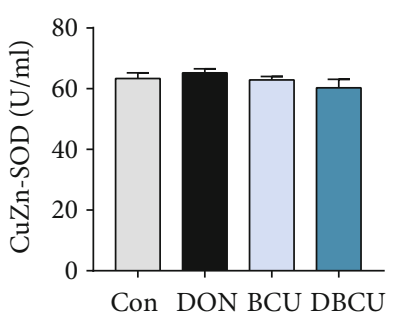

T-AOC

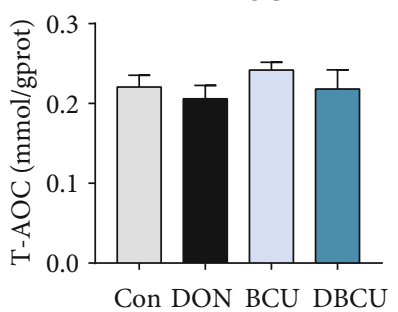

Mn-SOD

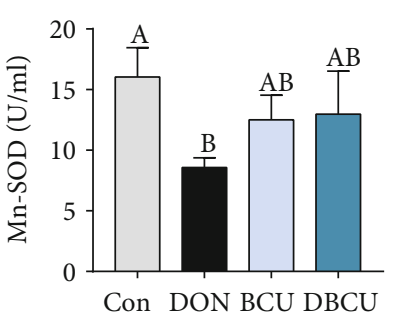

NO

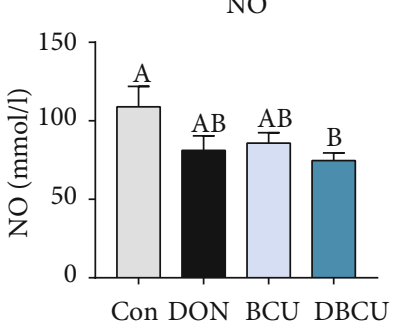

GSH

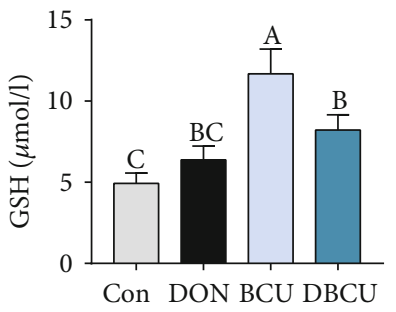

MDA

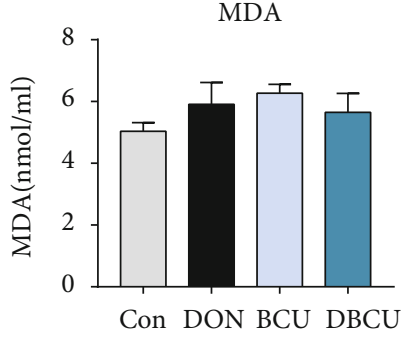

FIGURE 1: Effects of BCU on the serum antioxidant capacity of piglets challenged with DON $(n=7)$. Data are presented as mean \pm SEM; ${ }^{\mathrm{A}, \mathrm{B}}$ used to indicate a statistically significant difference $(p<0.05)$. Con: basal diet; DON: $4 \mathrm{mg} / \mathrm{kg}$ deoxynivalenol of basal diet; $\mathrm{BCU}$ : $5 \mathrm{~g} / \mathrm{kg}$ baicalin-copper of basal diet; DBCU: $4 \mathrm{mg} / \mathrm{kg}$ deoxynivalenol $+5 \mathrm{~g} / \mathrm{kg}$ baicalin-copper of basal diet.

GSH is an important antioxidant that can scavenge free radicals in the body. Dietary supplementation with BCU increases the concentration of GSH in serum. Yang et al. and Calabrese et al. showed that the addition of DON to feed resulted in oxidative stress in the jejunum of broiler chickens $[53,54]$. Therefore, we further measured the expression of intestinal antioxidant proteins. In the present study, dietary supplementation with DON markedly increased HO-1 protein expression in the jejunum and $\mathrm{HO}-1, \mathrm{p}-\mathrm{Nrf} 2$, and $\mathrm{p}-\mathrm{NF}-\kappa \mathrm{B}$ protein expression in the ileum. Compared with
DON supplementation, dietary supplementation with DON and BCU markedly decreased $\mathrm{HO}-1$ protein expression in the jejunum and $\mathrm{p}-\mathrm{Nrf} 2$, and $\mathrm{p}-\mathrm{NF}-\kappa \mathrm{B}$ contents in the ileum. These results indicate that dietary supplementation with $\mathrm{BCU}$ at $5 \mathrm{~g} / \mathrm{kg}$ diet can inhibit the expression of intestinal oxidative stress-related proteins in deoxynivalenol-challenged pigs. These results were similar to those of a previous study, which found that flavonoids activate antioxidant capacity and alleviate intestinal injury through the NF- $\kappa \mathrm{B}$ and $\mathrm{Nrf} 2$ pathway [55-57]. The liver is an important organ for the 

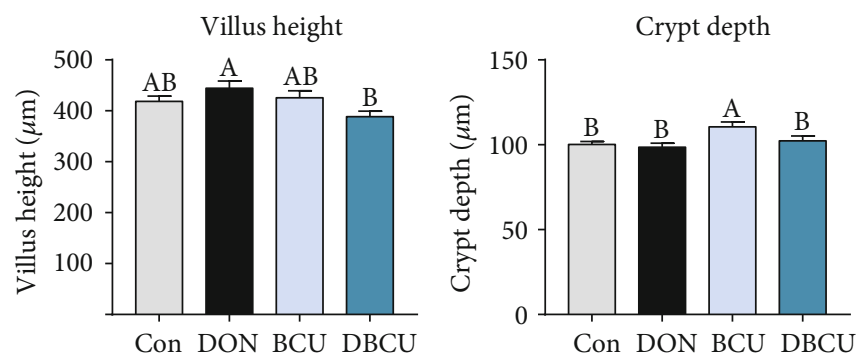

FIGURE 2: Effects of BCU on the jejunal morphology of piglets challenged with DON $(n=7)$. Data are presented as mean \pm SEM; ${ }^{\mathrm{A}, \mathrm{B}} \mathrm{used}$ to indicate a statistically significant difference $(p<0.05)$. Con: basal diet; DON: $4 \mathrm{mg} / \mathrm{kg}$ deoxynivalenol of basal diet; BCU: $5 \mathrm{~g} / \mathrm{kg}$ baicalincopper of basal diet; DBCU: $4 \mathrm{mg} / \mathrm{kg}$ deoxynivalenol $+5 \mathrm{~g} / \mathrm{kg}$ baicalin-copper of basal diet.
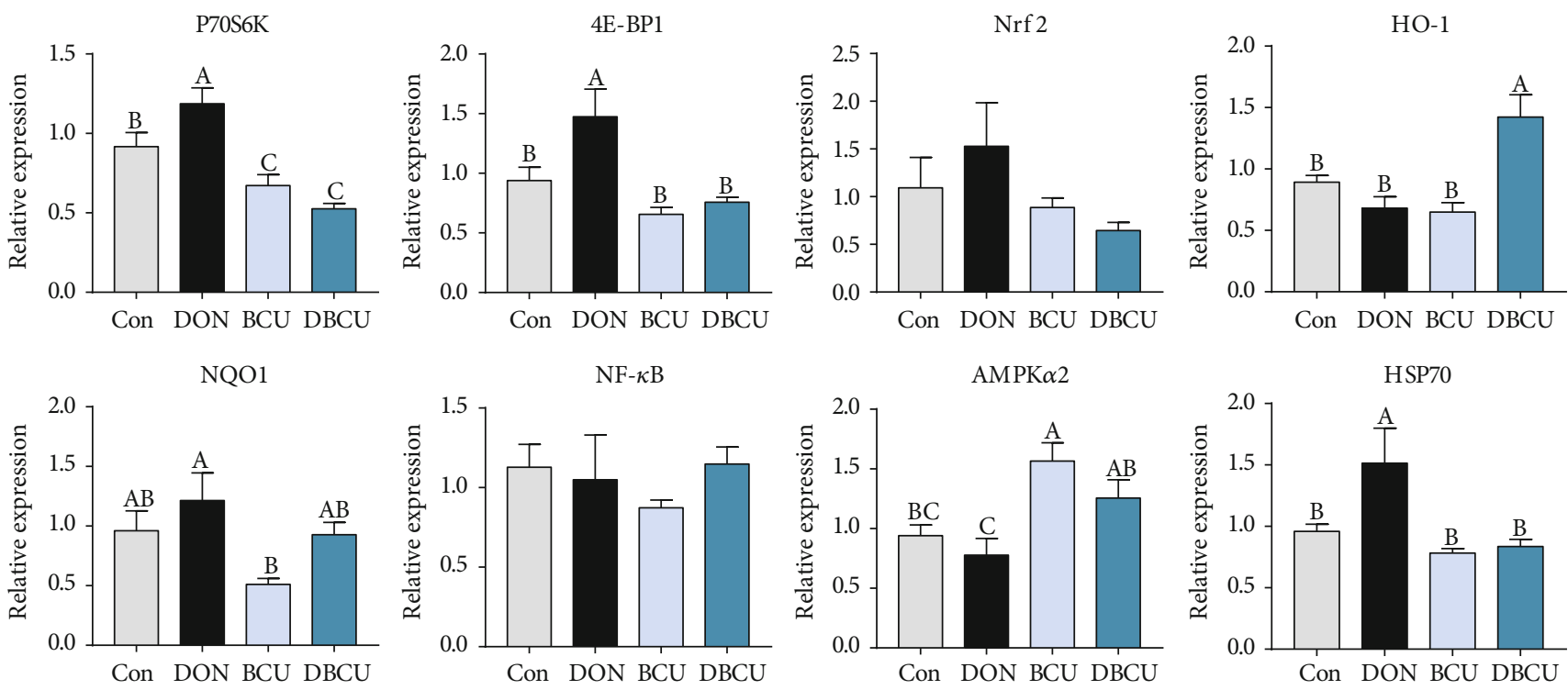

FIgURE 3: Effects of BCU on oxidative stress-related genes in the liver of piglets challenged with DON $(n=7)$. Data are presented as mean $\pm \mathrm{SEM} ;{ }^{\mathrm{A}-\mathrm{C}}$ used to indicate a statistically significant difference $(p<0.05)$. Con: basal diet; DON: $4 \mathrm{mg} / \mathrm{kg}$ deoxynivalenol of basal diet; BCU: $5 \mathrm{~g} / \mathrm{kg}$ baicalin-copper of basal diet; DBCU: $4 \mathrm{mg} / \mathrm{kg}$ deoxynivalenol $+5 \mathrm{~g} / \mathrm{kg}$ baicalin-copper of basal diet.
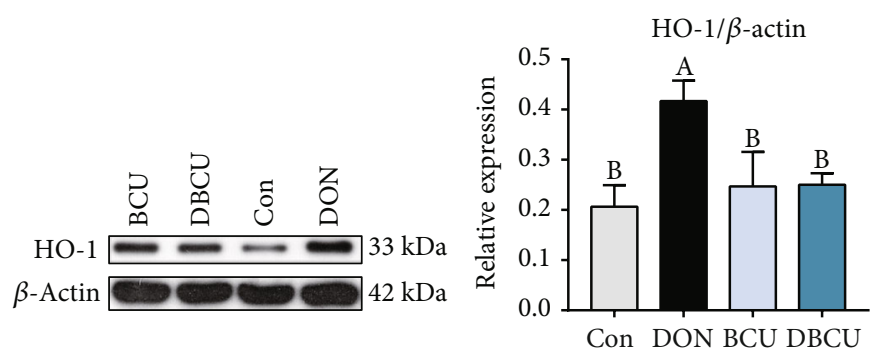

FIGURE 4: Effects of BCU on the relative protein level in the jejunum of piglets challenged with DON. Data are presented as mean \pm SEM; ${ }^{\mathrm{A}-\mathrm{C}}$ used to indicate a statistically significant difference $(p<0.05)$. Con: basal diet; DON: $4 \mathrm{mg} / \mathrm{kg}$ deoxynivalenol of basal diet; $\mathrm{BCU}$ : $5 \mathrm{~g} / \mathrm{kg}$ baicalin-copper of basal diet; DBCU: $4 \mathrm{mg} / \mathrm{kg}$ deoxynivalenol $+5 \mathrm{~g} / \mathrm{kg}$ baicalin-copper of basal diet.

detoxification of the body and has good antioxidant activities. Therefore, we detected the expression of antioxidant genes in the liver. Dietary supplementation with DON also markedly increased the mRNA levels of P70S6K, 4E-BP1, and HSP70 in the liver. Compared with DON supplementa- tion, dietary supplementation with DON and BCU obviously reduced the mRNA levels of P70S6K, 4E-BP1, and HSP70 and increased the mRNA levels of AMPK $\alpha 2$ and HO-1 in the liver. These results indicate that BCU can alleviate oxidative stress in the liver of DON-challenged pigs. Some 

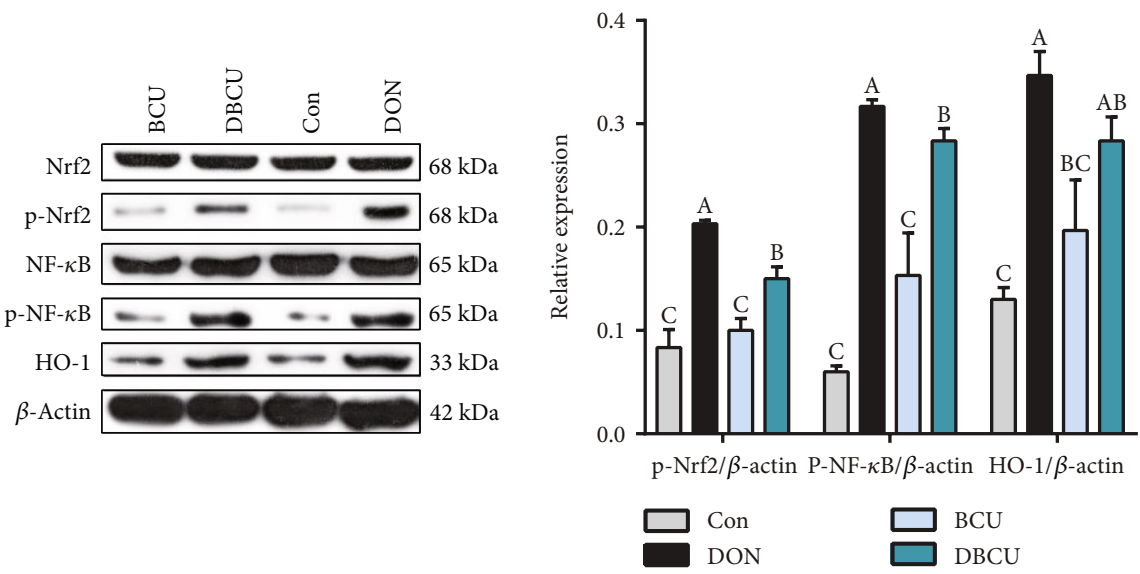

FIGURE 5: Effects of BCU on the relative protein level in the ileum of piglets challenged with DON. Data are presented as mean \pm SEM; ${ }^{\mathrm{A}-\mathrm{C}}$ used to indicate a statistically significant difference $(p<0.01)$. Con: basal diet; DON: $4 \mathrm{mg} / \mathrm{kg}$ deoxynivalenol of basal diet; BCU: $5 \mathrm{~g} / \mathrm{kg}$ baicalin-copper of basal diet; DBCU: $4 \mathrm{mg} / \mathrm{kg}$ deoxynivalenol $+5 \mathrm{~g} / \mathrm{kg}$ baicalin-copper of basal diet.
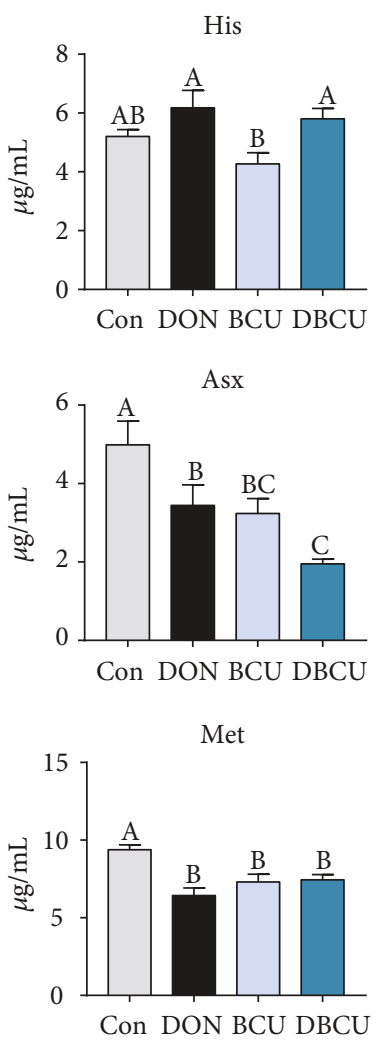

Pro

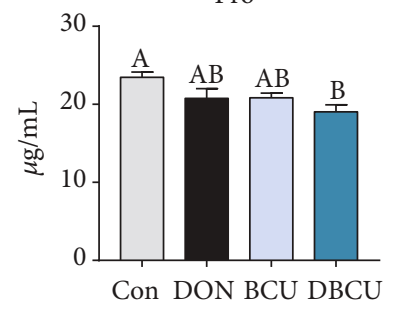

Ser

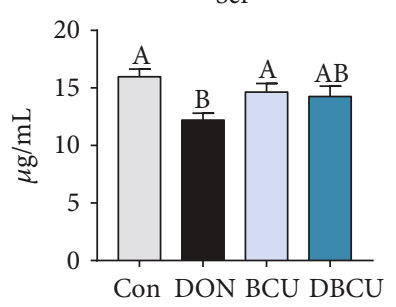

Thr

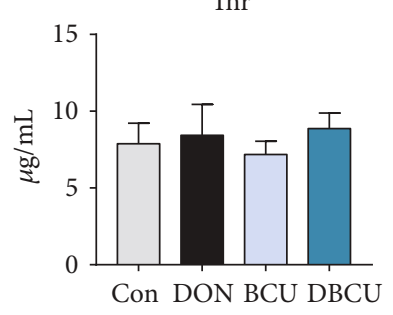

Val

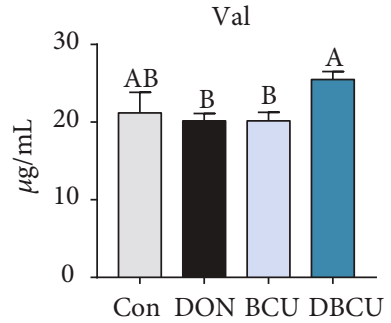

Cys

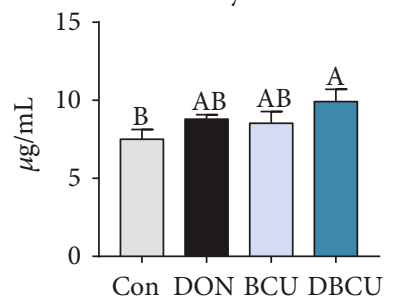

Arg

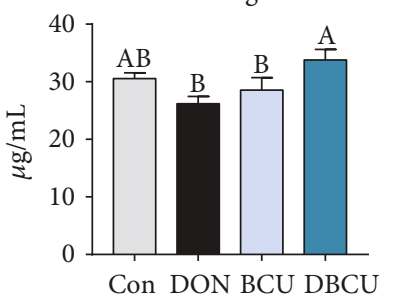

Ala
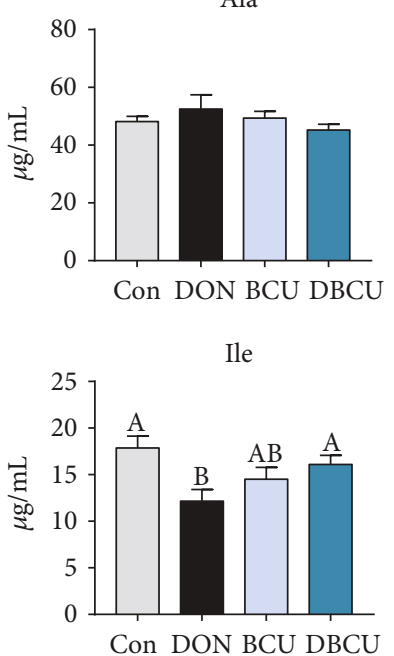

Lys

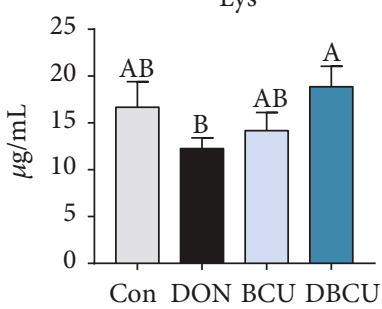

Glx

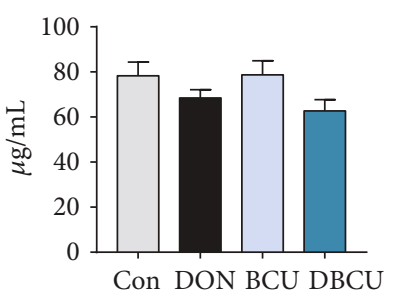

Glu

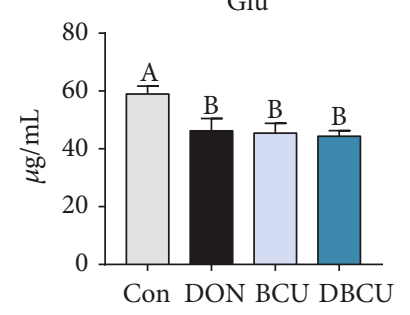

Leu

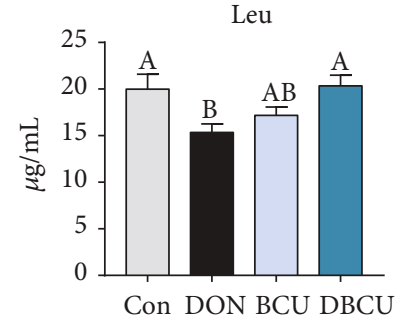

Tyr

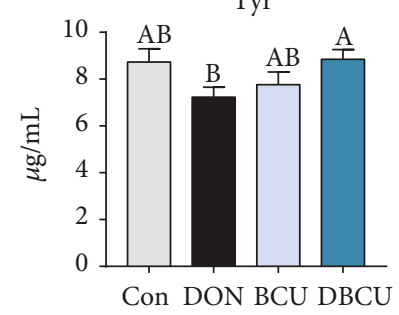

FIGURE 6: Effects of BCU on the free amino acids in the serum of piglets challenged with DON. Data are presented as mean \pm SEM; ${ }^{\mathrm{A}-\mathrm{C}}$ used to indicate a statistically significant difference $(p<0.05)$. Con: basal diet; DON: $4 \mathrm{mg} / \mathrm{kg}$ deoxynivalenol of basal diet; BCU: $5 \mathrm{~g} / \mathrm{kg}$ baicalincopper of basal diet, DBCU: $4 \mathrm{mg} / \mathrm{kg}$ deoxynivalenol $+5 \mathrm{~g} / \mathrm{kg}$ baicalin-copper of basal diet. 


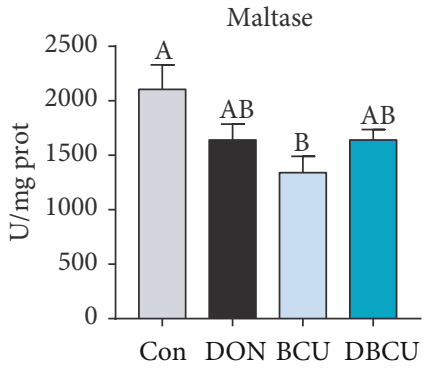

(a)

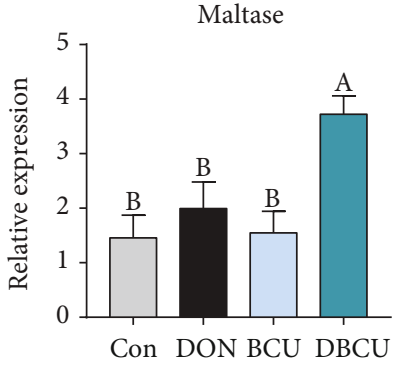

(b)
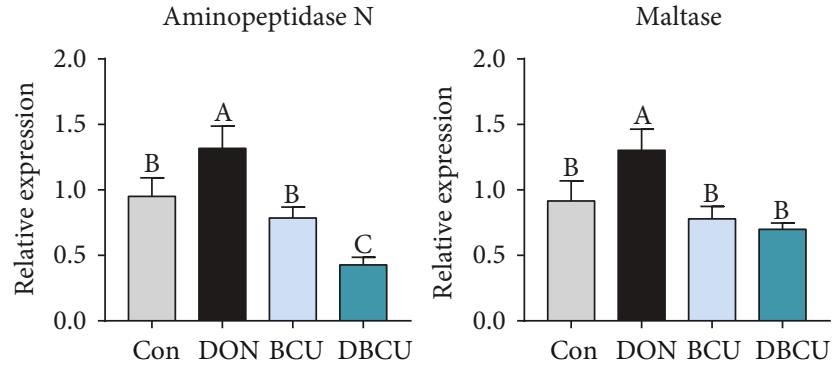

(c)

Figure 7: Effects of BCU on digestive enzyme-related genes in the intestine of piglets challenged with DON $(n=7)$. (a) Chyme maltase enzyme; (b) jejunum; (c) ileum. Data are presented as mean \pm SEM; ${ }^{A-C}$ used to indicate a statistically significant difference $(p<0.05)$. Con: basal diet; DON: $4 \mathrm{mg} / \mathrm{kg}$ deoxynivalenol of basal diet; BCU: $5 \mathrm{~g} / \mathrm{kg}$ baicalin-copper of basal diet; DBCU: $4 \mathrm{mg} / \mathrm{kg}$ deoxynivalenol $+5 \mathrm{~g} / \mathrm{kg}$ baicalin-copper of basal diet.
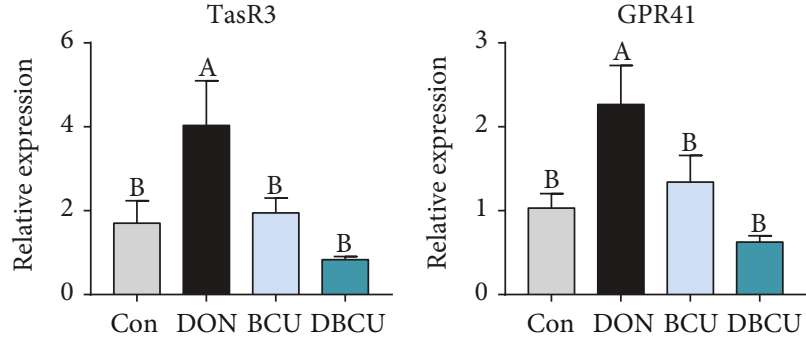

(a)

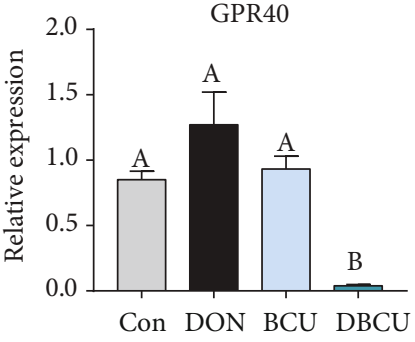

(b)

FIGURE 8: Effects of BCU on nutrient-sensing genes in the intestine of piglets challenged with DON ( $n=7)$. (a) Jejunum; (b) ileum. Data are presented as mean $\pm \mathrm{SEM} ;{ }^{\mathrm{A}-\mathrm{C}}$ used to indicate a statistically significant difference $(p<0.05)$. Con: basal diet; DON: $4 \mathrm{mg} / \mathrm{kg}$ deoxynivalenol of basal diet; BCU: $5 \mathrm{~g} / \mathrm{kg}$ baicalin-copper of basal diet; $\mathrm{DBCU}: 4 \mathrm{mg} / \mathrm{kg}$ deoxynivalenol $+5 \mathrm{~g} / \mathrm{kg}$ baicalin-copper of basal diet.
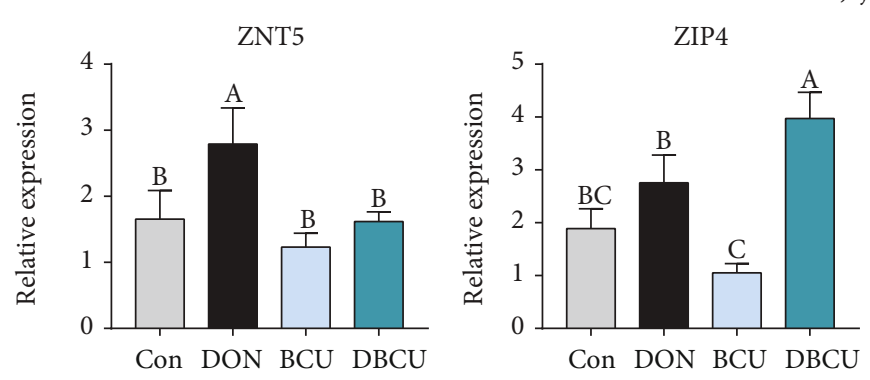

Jejunum
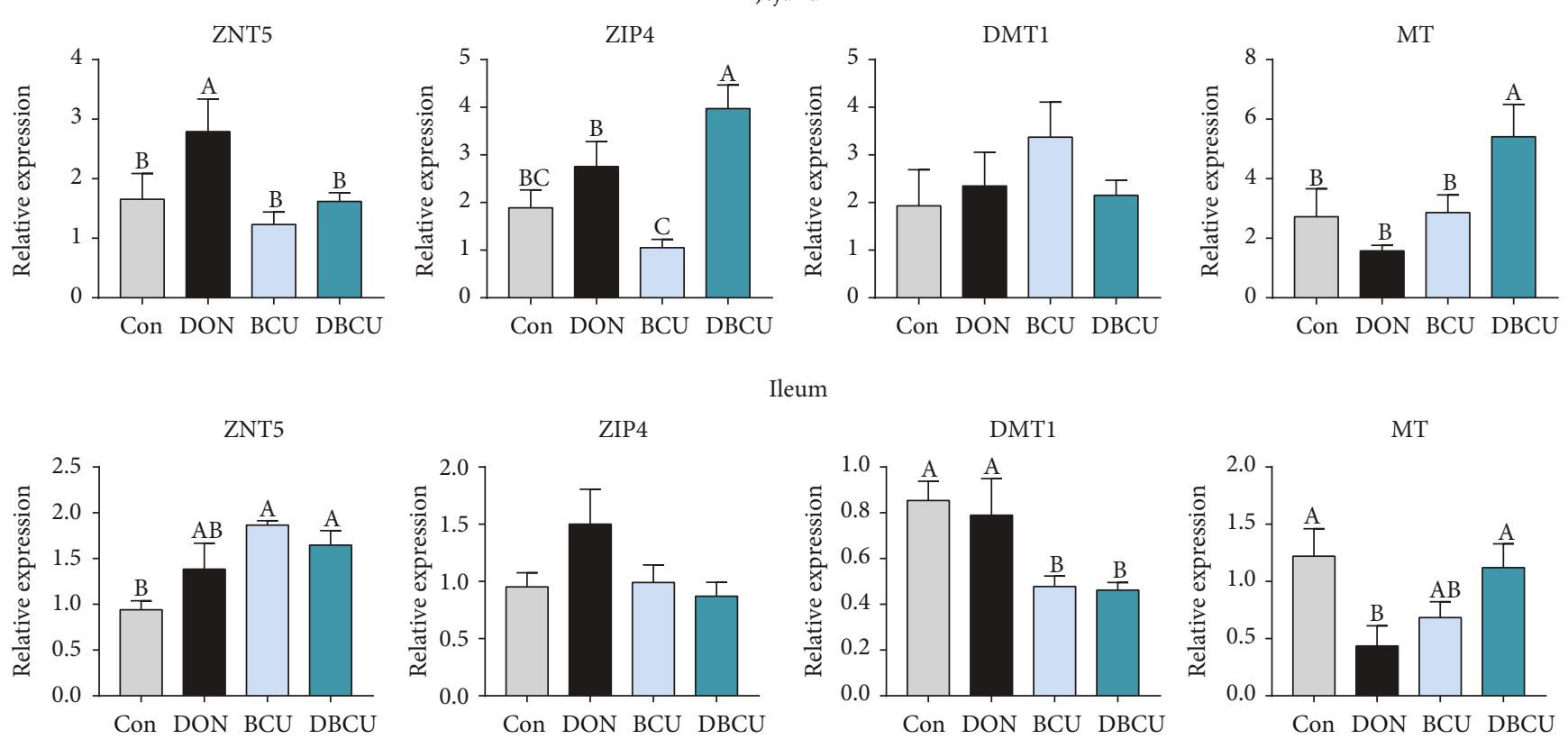

Ileum
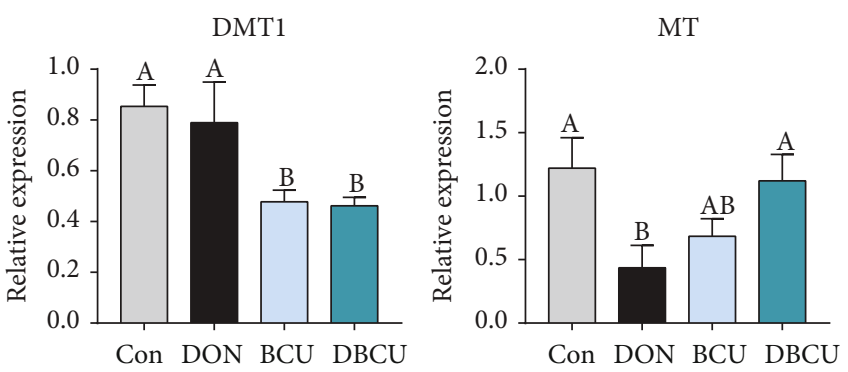

FIGURE 9: Effects of BCU on zinc transporter genes in the intestine of piglets challenged with DON $(n=7)$. Data are presented as mean \pm SEM; ${ }_{\mathrm{A}, \mathrm{B}}$ used to indicate a statistically significant difference $(p<0.05)$. Con: basal diet; DON: $4 \mathrm{mg} / \mathrm{kg}$ deoxynivalenol of basal diet; $\mathrm{BCU}$ : $5 \mathrm{~g} / \mathrm{kg}$ baicalin-copper of basal diet; DBCU: $4 \mathrm{mg} / \mathrm{kg}$ deoxynivalenol $+5 \mathrm{~g} / \mathrm{kg}$ baicalin-copper of basal diet. 
articles have also reported that flavonoids activate the AMPK pathway, inhibit the expression of Nrf2 and HO-1, and protect the liver in mice $[44,58,59]$. In conclusion, according to the intestinal, liver, and serum results, dietary supplementation with BCU improved the antioxidant capacity of piglets, thus alleviating the damage caused by DON.

It can be seen from the above findings that dietary supplementation with DON reduces growth performance and causes oxidative stress damage in piglets. The intestine is the primary target after DON enters the body. The decline in growth performance has a negligible link with intestinal damage by DON. Previous studies showed that DON can induce intestinal epithelial cell injury, change villus height and crypt depth in the intestine, and block the absorption of nutrients $[1,60,61]$. In the present study, the villus height in the DON group was significantly higher than that in the DBCU group, which was different from a previous study [10]. The digestion and absorption of nutrients in the intestine requires digestive enzymes. In the chyme, the maltase activity of the BCU group decreased. In the jejunum, the maltase mRNA levels of the DBCU group were significantly higher than those of the other three groups. In the ileum, the levels of aminopeptidase $\mathrm{N}$ and maltase mRNA of the DON group were significantly higher than those of the other three groups. This result may be because maltase in the DON group was damaged, so more maltase was produced for digestion. The absorption of nutrients by the intestines begins with nutrient-sensing genes. In the jejunum, TasR3 and GPR41 mRNA levels were significantly increased in the DON group, possibly because the DON group was nutrient deficient and thus expressed more receptors to absorb nutrients. Amino acids are the energy source of piglets, which are transported to various tissues with the blood. To understand the amino acid metabolism of piglets, we also measured the content of free amino acids in the blood. Lysine is the first restricted amino acid in pigs. The lack of lysine can lead to decreased growth performance in pigs. The serum lysine content in the DBCU group was significantly higher than that in the DON group, which means that BCU may increase the absorption of Lys in DONchallenged piglets. Phosphorylation is a common posttranslational modification that plays an important role in regulating signal transduction and gene expression [62, 63]. In eukaryotes, phosphorylation mainly occurs on serine, threonine, and tyrosine residues [28,62]. The current study showed that the Ser concentration of the DON group tended to be lower than that of the DBCU group. This result may be because DON promotes the phosphorylation of antioxidant-related proteins and consumes a large amount of serine, and dietary supplementation with DON and BCU can reduce the phosphorylation of antioxidantrelated proteins. In addition, the Leu concentration of the DON group was also markedly lower than that of the Con and DBCU groups. Leucine is not only a substrate for protein synthesis but also a key regulatory factor for protein synthesis in muscle tissues. The declined growth performance of the DON group may also be related to the blocked absorption of Leu $[64,65]$.

\section{Conclusions}

In summary, dietary BCU plays a beneficial role in alleviating the effect of DON on piglets, such as improving growth performance and antioxidant capacity and regulating intestinal nutrition absorption in weaned piglets. The results improve our understanding of the function of BCU in the intestine and support the application of BCU in animal production.

\section{Abbreviations}

ADG: $\quad$ Average daily gain

ADFI: $\quad$ Average daily feed intake

$\mathrm{AFB}_{1}$ : $\quad$ Aflatoxin $\mathrm{B}_{1}$

ALP: Alkaline phosphatase

ALT: $\quad$ Alanine aminotransferase

AST: $\quad$ Aspartate aminotransferase

Asx: $\quad$ L-Aspartic acid or L-asparagine

Arg: $\quad$ L-Arginine

Ala: L-Alanine

AMPK $\alpha 2: \quad$ AMP-activated protein kinase $\alpha 2$

AKT: $\quad$ AKT serine/threonine kinase 1

BCU: $\quad$ Baicalin-copper

BUN: Blood urea nitrogen

CHOL: Cholesterol

CR: Creatinine

CuZn-SOD: CuZn superoxide dismutase

Cys: L-Cystine

DMT1: Divalent metal transporter-1

DON: Deoxynivalenol

EAA: Essential amino acids

F/G: Feed/gain

GLU: $\quad$ Glucose

GSH-Px: Glutathione peroxidase

Glx: $\quad$ Glutamic acid or glutamine

Glu: $\quad$ L-Glutamate

GAPDH: Glyceraldehyde-3-phosphate dehydrogenase

GPR40: $\quad$ G protein-coupled receptors 40

GPR41: $\quad$ G protein-coupled receptors 41

His: $\quad$ L-Histidine

HO-1: $\quad$ Heme oxygenase-1

HSP70: $\quad$ Heat shock protein 70

Ile: L-Isoleucine

Lys: L-Lysine

Leu: $\quad$ L-Leucine

Mn-SOD: Mn superoxide dismutase

MDA: Malondialdehyde

Met: L-Methionine

MT: $\quad$ Metallothionein-1

NEAA: Nonessential amino acids

Nrf2: $\quad$ Nuclear factor erythroid-2-related factor 2

NQO1: $\quad \mathrm{NAD}(\mathrm{P}) \mathrm{H}$ quinone oxidoreductase-1

NF- $\kappa$ B: $\quad$ Nuclear factor kappa-B

Pro: $\quad$ L-Proline

Phe: $\quad$ L-Phenylalanine

P70S6K: $\quad$ Phosphorylated $70 \mathrm{kDa}$ ribosomal S6 kinase

Ser: $\quad$ L-Serine

T-AOC: Total antioxidizing capability

T-NOS: $\quad$ Total nitric oxide synthase 


$\begin{array}{ll}\text { T-SOD: } & \text { Total superoxide dismutase } \\ \text { Thr: } & \text { L-Threonine } \\ \text { Tyr: } & \text { L-Tyrosine } \\ \text { Try: } & \text { L-Tryptophan } \\ \text { TasR3: } & \text { Taste receptor type } 1 \text { member } 3 \\ \text { Val: } & \text { L-Valine } \\ \text { ZEN: } & \text { Zearalenone } \\ \text { ZNT1: } & \text { Zinc exporter } 1 \\ \text { ZNT2: } & \text { Zinc exporter } 2 \\ \text { ZNT5: } & \text { Zinc exporter } 5 \\ \text { ZIP4: } & \text { Zinc transporter } \\ \text { 4E-BP1: } & \text { eIF4E-binding protein } 1 .\end{array}$

\section{Data Availability}

All data used to support the findings of this study are included within the article.

\section{Conflicts of Interest}

The authors declare that no competing interests exist.

\section{Authors' Contributions}

Andong Zha, Peng Liao, and Bie Tan designed the research. Andong Zha, Daixiu Yuan, Zhijuan Cui, Ming Qi, and Simeng Liao performed the research. Andong Zha analysed the data. Andong Zha and Peng Liao wrote the paper with the help of all authors. All authors read and approved the final version of the manuscript.

\section{Acknowledgments}

This research was supported by the Fujian Provincial Science and Technology Department and Chinese Academy of Sciences Supporting Project of STS Program (2019T3033), the Technical Innovation Guidance Project of Guangxi Zhuang Autonomous Region Science and Technology Department (2018AC01007), the National Natural Science Foundation of China (31960666), the Natural Science Foundation of Hunan Province (2018JJ2464), and the Innovative Practice Training Program for College Students of the Chinese Academy of Sciences (KCJH801622015016).

\section{References}

[1] J. J. Pestka and A. T. Smolinski, "Deoxynivalenol: toxicology and potential effects on humans," Journal of Toxicology and Environmental Health, vol. 8, no. 1, pp. 39-69, 2005.

[2] J. J. Pestka, "Deoxynivalenol: mechanisms of action, human exposure, and toxicological relevance," Archives of Toxicology, vol. 84, no. 9, pp. 663-679, 2010.

[3] M. Bryla, E. Ksieniewicz-Wozniak, A. Waskiewicz, K. Szymczyk, and R. Jedrzejczak, "Natural occurrence of nivalenol, deoxynivalenol, and deoxynivalenol-3-glucoside in Polish winter wheat," Toxins, vol. 10, no. 2, p. 81, 2018.

[4] M. V. Silva, G. C. Pante, J. C. Z. Romoli et al., "Occurrence and risk assessment of population exposed to deoxynivalenol in foods derived from wheat flour in Brazil," Food Additives and Contaminants, vol. 35, no. 3, pp. 546-554, 2018.
[5] L. Wu, J. Li, Y. Li et al., "Aflatoxin B1, zearalenone and deoxynivalenol in feed ingredients and complete feed from different province in China," Journal of Animal Science and Biotechnology, vol. 7, no. 1, 2016.

[6] G. S. Shephard, P. G. Thiel, S. Stockenstrom, and E. W. Sydenham, "Worldwide survey of fumonisin contamination of corn and corn-based products," Journal of AOAC International, vol. 79, no. 3, pp. 671-687, 1996.

[7] J. H. Kouadio, S. D. Dano, S. Moukha, T. A. Mobio, and E. E. Creppy, "Effects of combinations of Fusarium mycotoxins on the inhibition of macromolecular synthesis, malondialdehyde levels, DNA methylation and fragmentation, and viability in Caco-2 cells," Toxicon, vol. 49, no. 3, pp. 306-317, 2007.

[8] H. Xiao, M. M. Wu, B. E. Tan et al., "Effects of composite antimicrobial peptides in weanling piglets challenged with deoxynivalenol: I. Growth performance, immune function, and antioxidation capacity," Journal of Animal Science, vol. 91, no. 10, pp. 4772-4780, 2013.

[9] L. Wu, P. Liao, L. He et al., "Growth performance, serum biochemical profile, jejunal morphology, and the expression of nutrients transporter genes in deoxynivalenol (DON)challenged growing pigs," BMC Veterinary Research, vol. 11, no. 1, 2015.

[10] H. Xiao, B. E. Tan, M. M. Wu et al., "Effects of composite antimicrobial peptides in weanling piglets challenged with deoxynivalenol: II. Intestinal morphology and function1," Journal of Animal Science, vol. 91, no. 10, pp. 4750-4756, 2013.

[11] Y. Tang, J. Li, F. Li et al., "Autophagy protects intestinal epithelial cells against deoxynivalenol toxicity by alleviating oxidative stress via IKK signaling pathway," Free Radical Biology \& Medicine, vol. 89, pp. 944-951, 2015.

[12] M. Lin, L. Li, L. Li et al., "The protective effect of baicalin against renal ischemia-reperfusion injury through inhibition of inflammation and apoptosis," BMC Complementary and Alternative Medicine, vol. 14, no. 1, 2014.

[13] B. Orzechowska, R. Chaber, A. Wisniewska et al., "Baicalin from the extract of Scutellaria baicalensis affects the innate immunity and apoptosis in leukocytes of children with acute lymphocytic leukemia," International Immunopharmacology, vol. 23, no. 2, pp. 558-567, 2014.

[14] Y. Gao, H. Liu, H. Wang et al., "Baicalin inhibits breast cancer development via inhibiting $\mathrm{I} \kappa \mathrm{B}$ kinase activation in vitro and in vivo," International Journal of Oncology, vol. 53, no. 6, pp. 2727-2736, 2018.

[15] Z. Ren, Z. Yang, Y. Li et al., "Effect of HBZn in repairing BNB in mice by alleviating anti-oxidative stress and activating hematogenous factors in optic nerve injury," Chinese Journal of Experimental Traditional Medical Formulae, vol. 23, no. 21, pp. 124-129, 2017.

[16] X. Li, K. Zou, J. Gou et al., "Effect of baicalin-copper on the induction of apoptosis in human hepatoblastoma cancer HepG2 cells," Medical oncology (Northwood, London, England), vol. 32, no. 3, 2015.

[17] Y. Liu, X. He, X. Liu et al., "Synthesis of baicalin-copper and baicalin-aluminium complex and its bioactivity," Zhongguo Zhong Yao Za Zhi, vol. 37, no. 9, pp. 1296-1302, 2012.

[18] L. Wu, P. Liao, L. He et al., "Dietary L-arginine supplementation protects weanling pigs from deoxynivalenol-induced toxicity," Toxins, vol. 7, no. 4, pp. 1341-1354, 2015. 
[19] H. L. Frobose, E. D. Fruge, M. D. Tokach et al., "The effects of deoxynivalenol-contaminated corn dried distillers grains with solubles in nursery pig diets and potential for mitigation by commercially available feed additives," Journal of Animal Science, vol. 93, no. 3, pp. 1074-1088, 2015.

[20] S. Kahlert, L. Renner, J. Kluess et al., "Effects of deoxynivalenol-feed contamination on circulating LPS in pigs," Innate Immunity, vol. 25, no. 3, pp. 168-175, 2019.

[21] Council, NR, Nutrient Requirements of Swine: Eleventh Revised Edition, The National Academies Press, Washington, DC, 2014.

[22] L. Jin, W. Wang, J. Degroote et al., "Mycotoxin binder improves growth rate in piglets associated with reduction of toll-like receptor-4 and increase of tight junction protein gene expression in gut mucosa," Journal of Animal Science and Biotechnology, vol. 8, no. 1, 2017.

[23] P. Rodjan, K. Soisuwan, K. Thongprajukaew et al., "Effect of organic acids or probiotics alone or in combination on growth performance, nutrient digestibility, enzyme activities, intestinal morphology and gut microflora in broiler chickens," Journal of Animal Physiology and Animal Nutrition, vol. 102, no. 2, pp. e931-e940, 2018.

[24] J. Wang, L. Zeng, B. Tan et al., "Developmental changes in intercellular junctions and $\mathrm{Kv}$ channels in the intestine of piglets during the suckling and post-weaning periods," Journal of Animal Science and Biotechnology, vol. 7, no. 1, pp. 1-10, 2016.

[25] X. Xiong, H. S. Yang, X. C. Wang et al., "Effect of low dosage of chito-oligosaccharide supplementation on intestinal morphology, immune response, antioxidant capacity, and barrier function in weaned piglets," Journal of Animal Science, vol. 93, no. 3, pp. 1089-1097, 2015.

[26] W. Jiang, S. Nie, Z. Qu, C. Bi, and A. Shan, "The effects of conjugated linoleic acid on growth performance, carcass traits, meat quality, antioxidant capacity, and fatty acid composition of broilers fed corn dried distillers grains with solubles," Poultry Science, vol. 93, no. 5, pp. 1202-1210, 2014.

[27] W. Zhu, D. Li, J. Wang et al., "Effects of polymannuronate on performance, antioxidant capacity, immune status, cecal microflora, and volatile fatty acids in broiler chickens," Poultry Science, vol. 94, no. 3, pp. 345-352, 2015.

[28] G. Wu, "Amino acids: metabolism, functions, and nutrition," Amino Acids, vol. 37, no. 1, pp. 1-17, 2009.

[29] P. Liao, M. Liao, L. Li, B. Tan, and Y. Yin, "Effect of deoxynivalenol on apoptosis, barrier function, and expression levels of genes involved in nutrient transport, mitochondrial biogenesis and function in IPEC-J2 cells," Toxicology Research, vol. 6, no. 6, pp. 866-877, 2017.

[30] J. K. Lunney, "Advances in swine biomedical model genomics," International Journal of Biological Sciences, vol. 3, no. 3, pp. 179-184, 2007.

[31] S. Yan, L. Long, E. Zong et al., "Dietary sulfur amino acids affect jejunal cell proliferation and functions by affecting antioxidant capacity, Wnt/ $\beta$-catenin, and the mechanistic target of rapamycin signaling pathways in weaning piglets," Journal of Animal Science, vol. 96, no. 12, pp. 5124-5133, 2018.

[32] F. Li, J. Wang, L. Huang, H. Chen, and C. Wang, "Effects of adding Clostridium sp. WJ06 on intestinal morphology and microbial diversity of growing pigs fed with natural deoxynivalenol contaminated wheat," Toxins, vol. 9, no. 12, p. 383, 2017.
[33] B. Bergsjo, T. Matre, and I. Nafstad, "Effects of diets with graded levels of deoxynivalenol on performance in growing pigs," Journal of Veterinary Medicine Series A, vol. 39, no. 10, pp. 752-758, 1992.

[34] T. Goyarts, S. Danicke, H. J. Rothkotter, J. Spilke, U. Tiemann, and M. Schollenberger, "On the effects of a chronic deoxynivalenol intoxication on performance, haematological and serum parameters of pigs when diets are offered either for ad libitum consumption or fed restrictively," Journal of Veterinary Medicine. A, Physiology, Pathology, Clinical Medicine, vol. 52, no. 6, pp. 305-314, 2005.

[35] Q. Deng, J. Xu, B. Yu et al., "Effect of dietary tea polyphenols on growth performance and cell-mediated immune response of post-weaning piglets under oxidative stress," Archives of Animal Nutrition, vol. 64, no. 1, pp. 12-21, 2010.

[36] F. Goodarzi Boroojeni, K. Manner, and J. Zentek, "The impacts of Macleaya cordata extract and naringin inclusion in post-weaning piglet diets on performance, nutrient digestibility and intestinal histomorphology," Archives of Animal Nutrition, vol. 72, no. 3, pp. 178-189, 2018.

[37] Y. Zhou, S. Mao, and M. Zhou, "Effect of the flavonoid baicalein as a feed additive on the growth performance, immunity, and antioxidant capacity of broiler chickens," Poultry Science, vol. 98, no. 7, pp. 2790-2799, 2019.

[38] Z. H. Song, K. Cheng, X. C. Zheng, H. Ahmad, L. L. Zhang, and T. Wang, "Effects of dietary supplementation with enzymatically treated Artemisia annua on growth performance, intestinal morphology, digestive enzyme activities, immunity, and antioxidant capacity of heat-stressed broilers," Poultry Science, vol. 97, no. 2, pp. 430-437, 2018.

[39] Z. Peng, Y. Liao, L. Chen et al., "Heme oxygenase-1 attenuates low-dose of deoxynivalenol-induced liver inflammation potentially associating with microbiota," Toxicology and Applied Pharmacology, vol. 374, pp. 20-31, 2019.

[40] J. Ji, P. Zhu, F. Cui, F. Pi, Y. Zhang, and X. Sun, “The disorder metabolic profiling in kidney and spleen of mice induced by mycotoxins deoxynivalenol through gas chromatography mass spectrometry," Chemosphere, vol. 180, pp. 267-274, 2017.

[41] S. Chen, Y. H. Li, and M. F. Lin, "Chronic exposure to the Fusarium mycotoxin deoxynivalenol: impact on performance, immune organ, and intestinal integrity of slow-growing chickens," Toxins, vol. 9, no. 10, p. 334, 2017.

[42] U. Tiemann and S. Danicke, "In vivo and in vitro effects of the mycotoxins zearalenone and deoxynivalenol on different nonreproductive and reproductive organs in female pigs: a review," Food Additives and Contaminants, vol. 24, no. 3, pp. 306-314, 2007.

[43] F. Yildiz, A. Terzi, S. Coban et al., "Purified micronized flavonoid fraction ameliorates the injury of spleen and ileum secondary to hepatic ischemia-reperfusion in rats," Digestive Diseases and Sciences, vol. 55, no. 8, pp. 22372243, 2010.

[44] K. Madushani Herath, J. Cho, A. Kim et al., "Phenolic acid and flavonoid-rich fraction of Sasa quelpaertensis Nakai leaves prevent alcohol induced fatty liver through AMPK activation," Journal of Ethnopharmacology, vol. 224, pp. 335-348, 2018.

[45] J. J. Pestka and C. J. Amuzie, "Tissue distribution and proinflammatory cytokine gene expression following acute oral exposure to deoxynivalenol: comparison of weanling and adult mice," Food and Chemical Toxicology, vol. 46, no. 8, pp. 28262831, 2008 
[46] B. A. Rotter, D. B. Prelusky, and J. J. Pestka, "Toxicology of deoxynivalenol (vomitoxin)," Journal of Toxicology and Environmental Health, vol. 48, no. 1, pp. 1-34, 1996.

[47] H. R. Zhou, Q. Jia, and J. J. Pestka, "Ribotoxic stress response to the trichothecene deoxynivalenol in the macrophage involves the SRC family kinase Hck," Toxicological Sciences, vol. 85, no. 2, pp. 916-926, 2005.

[48] Y. Sugita-Konishi and J. J. Pestka, "Differential upregulation of TNF-alpha, IL-6, and IL-8 production by deoxynivalenol (vomitoxin) and other 8-ketotrichothecenes in a human macrophage model," Journal of Toxicology and Environmental Health. Part A, vol. 64, no. 8, pp. 619-636, 2001.

[49] B. Halliwell and J. Gutteridge, Free Radicals in Biology and Medicine, Oxford University Press, USA, 3rd edition, 2015.

[50] A. Mishra, S. Kumar, and A. K. Pandey, "Scientific Validation of the Medicinal Efficacy of Tinospora cordifolia," The Scientific World Journal, vol. 2013, Article ID 292934, 8 pages, 2013.

[51] G. B. Bubols, R. Vianna Dda, A. Medina-Remon et al., "The antioxidant activity of coumarins and flavonoids," Mini Reviews in Medicinal Chemistry, vol. 13, no. 3, pp. 318-334, 2013.

[52] L. Selloum, S. Reichl, M. Muller, L. Sebihi, and J. Arnhold, "Effects of flavonols on the generation of superoxide anion radicals by xanthine oxidase and stimulated neutrophils," Archives of Biochemistry and Biophysics, vol. 395, no. 1, pp. 49-56, 2001.

[53] X. Yang, L. Li, Y. Duan, and X. Yang, “Antioxidant activity of JM113 in vitro and its protective effect on broiler chickens challenged with deoxynivalenol," Journal of Animal Science, vol. 95, no. 2, pp. 837-846, 2017.

[54] G. Calabrese, B. Morgan, and J. Riemer, "Mitochondrial glutathione: regulation and functions," Antioxidants \& Redox Signaling, vol. 27, no. 15, pp. 1162-1177, 2017.

[55] D. Ferrari, A. Speciale, M. Cristani et al., "Cyanidin-3-O-glucoside inhibits NF-kB signalling in intestinal epithelial cells exposed to TNF- $\alpha$ and exerts protective effects via Nrf2 pathway activation,” Toxicology Letters, vol. 264, pp. 51-58, 2016.

[56] B. D. Sahu, J. M. Kumar, and R. Sistla, "Fisetin, a dietary flavonoid, ameliorates experimental colitis in mice: Relevance of NF- $\kappa$ Bsignaling," The Journal of Nutritional Biochemistry, vol. 28, pp. 171-182, 2016.

[57] S. De Spirt, A. Eckers, C. Wehrend et al., "Interplay between the chalcone cardamonin and selenium in the biosynthesis of Nrf2-regulated antioxidant enzymes in intestinal Caco-2 cells," Free Radical Biology \& Medicine, vol. 91, pp. 164-171, 2016.

[58] T. Goto, A. Teraminami, J. Y. Lee et al., "Tiliroside, a glycosidic flavonoid, ameliorates obesity-induced metabolic disorders via activation of adiponectin signaling followed by enhancement of fatty acid oxidation in liver and skeletal muscle in obesediabetic mice," The Journal of Nutritional Biochemistry, vol. 23, no. 7, pp. 768-776, 2012.

[59] Y. He, Z. Xia, D. Yu et al., "Hepatoprotective effects and structure-activity relationship of five flavonoids against lipopolysaccharide/d-galactosamine induced acute liver failure in mice," International Immunopharmacology, vol. 68, pp. 171-178, 2019.

[60] P. Pinton and I. P. Oswald, "Effect of deoxynivalenol and other type B trichothecenes on the intestine: a review," Toxins, vol. 6, no. 5, pp. 1615-1643, 2014.
[61] K. Ghareeb, W. A. Awad, J. Bohm, and Q. Zebeli, "Impacts of the feed contaminant deoxynivalenol on the intestine of monogastric animals: poultry and swine," Journal of Applied Toxicology: JAT, vol. 35, no. 4, pp. 327-337, 2015.

[62] T. Hunter, "Signaling-2000 and beyond," Cell, vol. 100, no. 1, pp. 113-127, 2000.

[63] J. H. Kim, J. Lee, B. Oh, K. Kimm, and I. Koh, "Prediction of phosphorylation sites using SVMs," Bioinformatics (Oxford, England), vol. 20, no. 17, pp. 3179-3184, 2004.

[64] Y. Duan, F. Li, H. Liu et al., "Nutritional and regulatory roles of leucine in muscle growth and fat reduction," Frontiers in bioscience (Landmark edition), vol. 20, pp. 796-813, 2015.

[65] F. Li, Y. Yin, B. Tan, X. Kong, and G. Wu, "Leucine nutrition in animals and humans: mTOR signaling and beyond," Amino Acids, vol. 41, no. 5, pp. 1185-1193, 2011. 


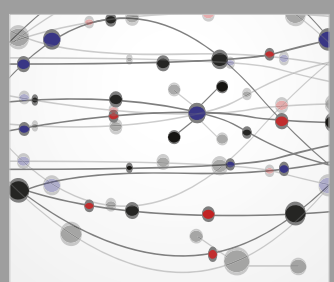

The Scientific World Journal
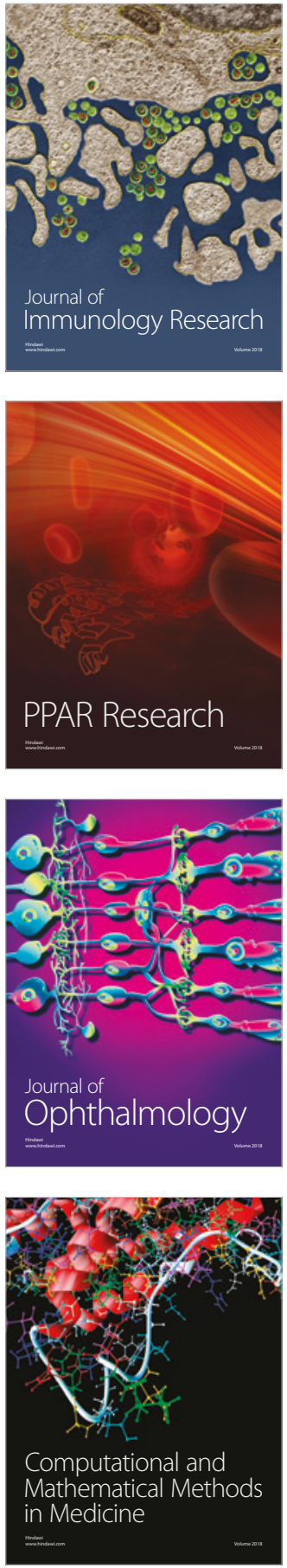

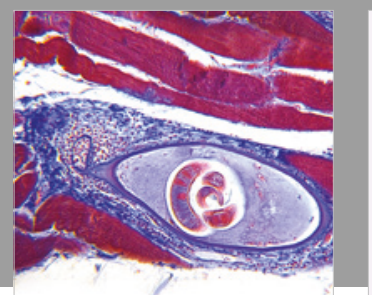

Gastroenterology Research and Practice

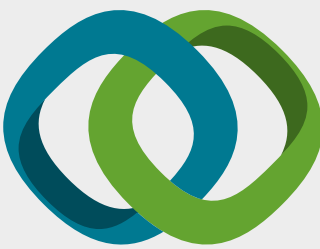

\section{Hindawi}

Submit your manuscripts at

www.hindawi.com
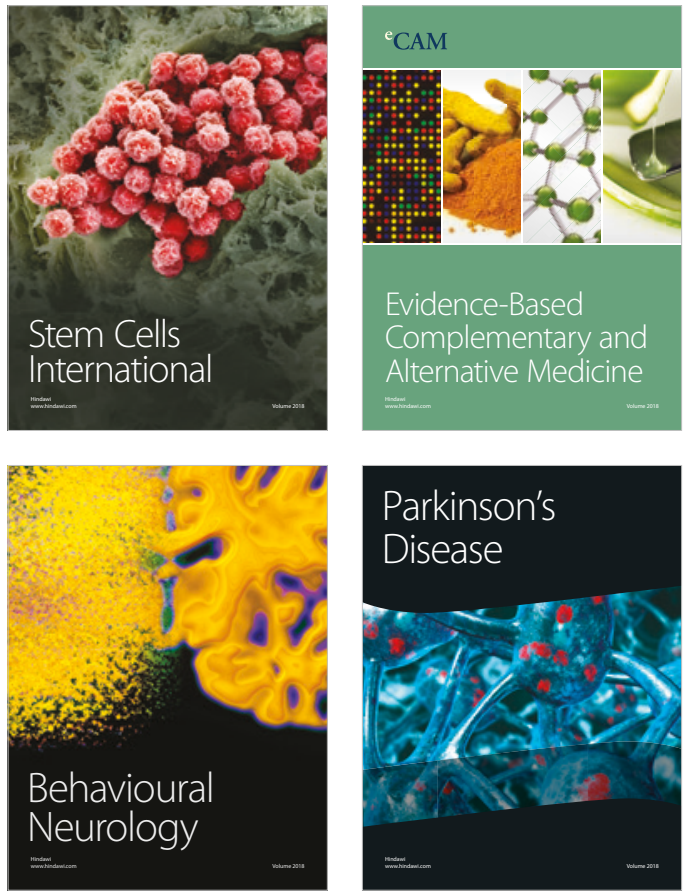

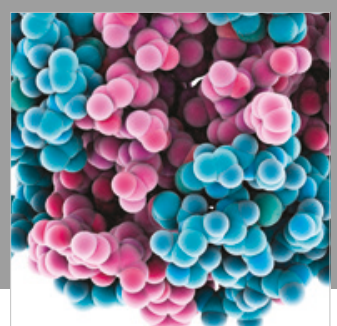

ournal of

Diabetes Research

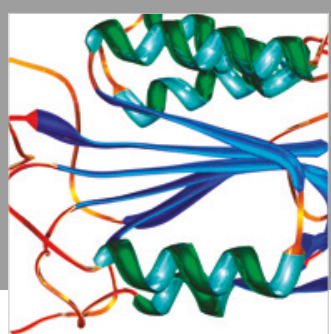

Disease Markers
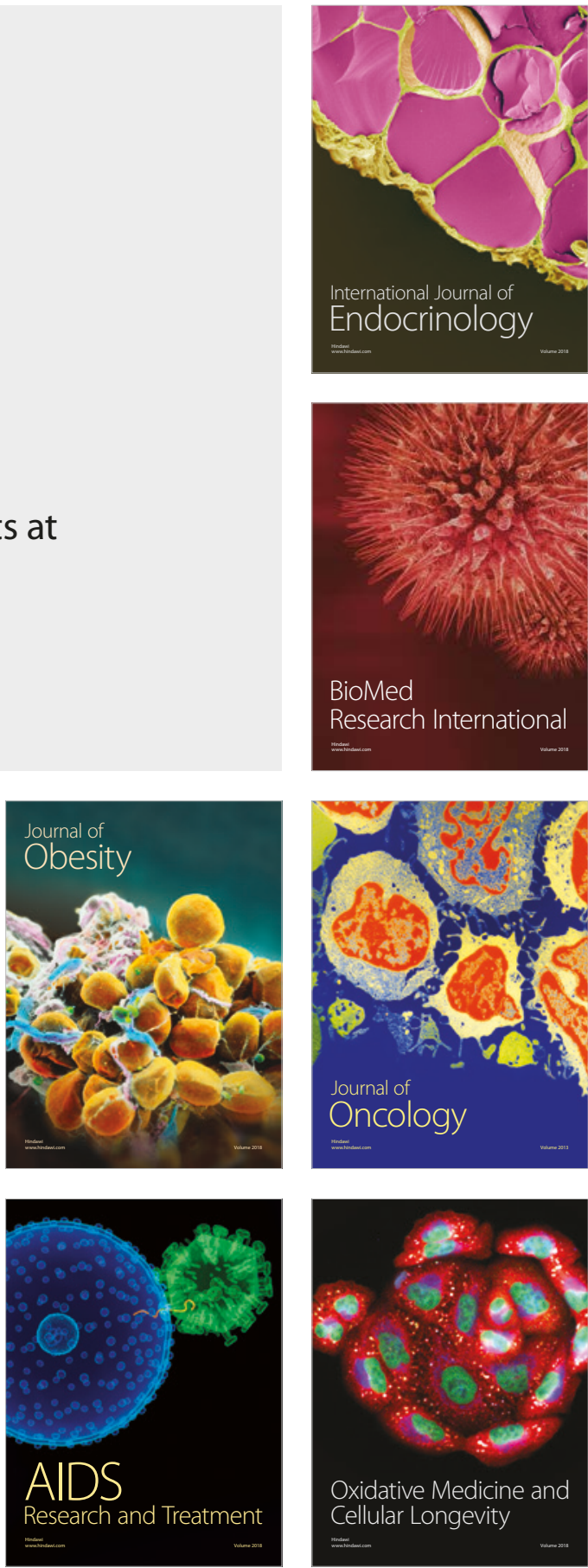